\title{
Pengaruh Status Sosial Ekonomi Orang Tua dan Motivasi Belajar Terhadap Hasil Belajar Siswa
}

\author{
Yola Fatmasari'), Luluh Abdillah Kurniawan') \\ 1,2 ) Program Studi Pendidikan Ekonomi, Universitas Panca Sakti Bekasi \\ Correspondence author: Yola Fatmasari, Yolafatmasari0202@gmail.com
}

DOI : https://doi.org/10.37012/jipmht.v5i1.726

\begin{abstract}
ABSTRAK
Tujuan dari penelitian ini adalah untuk menyelidiki apakah ada pengaruh status social ekonomi orang tua dan motivasi belajar terhadap hasil belajar siswa di SMP Shidqia Islamic School. Metode yang dipakai dalam penelitian ini adalah kuantitatif asosiatif. Teknik pengambilan sampel menggunakan total samping dengan jumlah sampel sebanyak 150 siswa di SMP Shidqia Islamic School Bekasi. Data yang digunakan adalah analisis regresi $\mathrm{Y}$ dan $\mathrm{X}$ sebesar 74.431+0.112 X. Dari analisis diperoleh t hit 7.289

dan $\mathrm{p}$-value $=0,002<0,05$ atau Ho ditolak. Dengan demikian koefisien korelasi $\mathrm{X}$ dan $\mathrm{Y}$ adalah signifikan, sedangkan hasil pengujian regresi menunjukan bahwa koefisien determinan sebesar 0.393 atau $39,3 \%$. Kondisi sosial ekonomi orang tua yang relatif rendah, sehingga pihak sekolah hendaknya memberikan petunjuk dan informasi kepada orang tua tentang adanya beasiswa yang jelas dan komprehensif agar siswa dapat mencapai hasil belajar yang prima, dan pihak sekolah serta orang tua juga memberikan motivasi yang maksimal kepada siswa. belajar menjadi kebiasaan yang dilakukan secara rutin.
\end{abstract}

Kata kunci: Status Sosial Ekonomi Orang Tua, Motivasi Belajar, Hasil Belajar

\section{ABSTRACT}

The purpose of this study was to investigate whether there is an effect of parents' socioeconomic status and learning motivation on student learning outcomes at SMP Shidqia Islamic School. The method used in this research is quantitative associative. The sampling technique used a side total with a total sample of 150 students at SMP Shidqia Islamic School Bekasi. The data used is $Y$ and X regression analysis of $74.431+0.112 X$. From the analysis obtained thit 7.289 and $p$-value $=0.002<0.05$ or Ho is rejected Thus the correlation coefficient of $X$ and $Y$ is significant, while the results of the regression test show that the determinant coefficient is 0.393 or $39.3 \%$. The socio-economic conditions of parents are relatively low, so the school should provide instructions and information to parents about the existence of clear and comprehensive scholarships so that students can achieve excellent learning outcomes, and the school and parents also provide maximum motivation to students. learning becomes a habit that is done regularly.

Keywords: Parents' Sosioeconomic Status, Motivation to learn, Learning outcomes 


\section{PENDAHULUAN}

Status ekonomi merupakan gabungan antara status sosial dan status ekonomi yang dimiliki oleh orang tua dalam kelompok masyarakat, sehingga Soekanto juga mengatakan: "Status sosial adalah tempat secara umum di dalam masyarakat, sehubungan dengan orang lain dalam arti lingkungan pergaulannya, prestise dan hak- hak serta kewajiban- kewajibannya". (2021'210). "Status sosial adalah kedudukan seseorang (individu) dalam suatu kelompok kehidupan sosial" (Susanto. 2004;195). John W. Santrock (2009: 194) menunjukkan bahwa "status sosial ekonomi adalah kategorisasi orang menurut karakteristik ekonomi, pendidikan dan profesional mereka.". Sedangkan Sugihartono (2007:30) menyatakan bahwa "status sosial ekonomi orang tua meliputi tingkat pendidikan orang tua, pekerjaan orang tua, dan pendapatan orang tua". Jadi status sosial yang dimaksud disini adalah kedudukan seseorang dalam suatu masyarakat sedangkan status ekonomi lebih menitikberatkan pada pendapatan daripada yang dimiliki seseorang.

Motivasi adalah pengejawantahan dari motivasi-motivasi potensial dalam diri individu yang akan terwujud dalam bentuk tingkah laku yang sebenarnya, sesuai dengan situasi yang dihadapinya. Motivasi membentuk pada konsep yang akan digunakan untuk menjelaskan kekuatan-kekuatan yang ada dan bertindak pada organisme atau individu, yang merupakan kekuatan pendorong dan arah perilaku individu untuk meraih tujuan tertentu. Dengan motivasi, seseorang dapat mengambil tindakan. Jika tidak ada motivasi maka individu tidak dapat mencapai apa yang sudah menjadi tujuannya, ada faktor yang mempengaruhi motivasi yaitu faktor individu dan faktor lingkungan. Dalam kondisi yang membutuhkan prestasi, individu dengan motivasi berprestasi akan didorong untuk terlibat dalam perilaku tertentu untuk memenuhi atau melebihi standar keunggulan.

Menurut Kamus Besar Bahasa Indonesia, hasil memiliki arti yang berbeda; 1) Sesuatu yang dimiliki perusahaan, 2) pendapatan; Akuisisi; buah Sedangkan belajar adalah perubahan tingkah laku atau reaksi yang disebabkan oleh pengalaman. Hasil belajar adalah suatu proses untuk melihat sejauh mana siswa mampu menguasai atau memahami pembelajaran setelah mengikuti kegiatan proses belajar mengajar, atau suatu prestasi yang diungkapkan siswa setelah mengikuti kegiatan belajar berupa huruf, angka atau. Simbol-simbol tertentu tercapai, yang disetujui oleh para siswa. Hasil belajar merupakan keterampilan yang dimiliki siswa setelah menjalani 
pengalaman dalam hal perubahan aspek kognitif yang dicapai berupa angka, skor, dan faktorfaktor yang mempengaruhi mereka secara internal dan eksternal. Teknik pengujian dapat dibagi menjadi beberapa kelompok berdasarkan penampilan dan alasan klasifikasi. Sebagai salah satunya, tes dibagi menurut fungsinya yaitu tes masuk, tes awal, tes akhir, formatif, sumatif dan diagnostik. Sedangkan teknik no-test juga dibagi menjadi beberapa bagian kelompok yang meliputi observasi (observasi), wawancara (interviews), angket (questionnaires), skala likert dan lain-lain. Dalam kedua teknik tersebut dapat digunakan untuk mendapatkan informasi maupun data dari objek yang akan diteliti.

Berdasarkan latar belakang tersebut, penelitian ini bertujuan untuk mengetahui hubungan antara status sosial ekonomi orang tua serta motivasi belajar dengan hasil belajar siswa di SMP Shidqia Islamic School.

\section{METODE PENELITIAN}

Penelitian ini menggunakan metode kuantitatif. Penelitian kuantitatif adalah penelitian yang menggunakan angka secara ekstensif, yaitu dari mengumpulkan data hingga menafsirkan data yang diperoleh dan menyajikan hasilnya. (Arikunto, 2019). Jenis penelitian ini yaitu eksperimen (Creswell, 2012). Penelitian ini dilakukan di SMP Shidqia Islamic School, dengan jumlah sampel 150 siswa. Teknik pengumpulan data dalam penelitian ini adalah dengan menyebarkan kuesioner atau angket untuk mengetahui ada tidaknya pengaruh variabel $\mathrm{X}$ dan $\mathrm{Y}$ dengan menggunakan pertanyaan yang harus dijawab dengan jujur oleh responden atau siswa. observasi dengan metode ini, penulis secara langsung mengamati objek yang akan diteliti. Dan data dokumentasi untuk mengetahui nilai (hasil belajar siswa), jumlah guru dan staf, jumlah siswa, struktur organisasi sekolah, sarana dan prasarana sekolah. Pengambilan sampel menggunakan total sampling. Variabel pencarian adalah bentuk tindakan seseorang yang menunjukkan variasi antara satu objek dengan objek lainnya. Variabel bebas penelitian ini adalah Status Sosial Ekonomi Orang Tua dan Motivasi Belajar Siswa. Sedangkan variabel yang terikat dalam penelitian ini ialah Hasil Belajar Siswa 


\section{HASIL DAN PEMBAHASAN}

\section{Skor Status Sosial Ekonomi Orang Tua}

Dari skor kuesioner Status Sosial Ekonomi dengan jumlah responden 150 siswa, didapatkan skor terendah 53 dan skor tertinggi 76, rentang skor 23, rata- rata skor sebesar 66.60, simpanan baku 4.948, modus 67, dan median 67.00.

\begin{tabular}{lll}
\multicolumn{3}{c}{ Tabel 1 } \\
\multicolumn{3}{c}{ Status Sosial Ekonomi } \\
\hline \multirow{3}{*}{ Okuran } \\
No & Deskriptif & Nilai \\
\hline 1 & Mode & 67 \\
2 & Median & 67.00 \\
3 & Mean & 66.60 \\
4 & Simpangan Baku & 4.948 \\
5 & Varians & 24.483 \\
\hline Sumber : & Peneliti (2021) &
\end{tabular}

\section{Skor Motivasi Belajar}

Dari skor kuesioner Motivasi Belajar jumlah responden 150 siswa, didapatkan skor terendah 28 dan skor tertinggi 52, rentang skor 24, rata- rata skor sebesar 41.69, simpanan baku 4.852, modus 43, dan median 42.00.

Tabel 2

\begin{tabular}{lll}
\multicolumn{3}{c}{ Motivasi Belajar } \\
\hline & Ukuran & Nilai \\
No & Deskriptif & 43 \\
\hline 1 & Mode & 42.00 \\
2 & Median & 41.69 \\
3 & Mean & 4.852 \\
4 & Simpangan Baku & 23.545 \\
5 & Varians & \\
\hline
\end{tabular}

Sumber : Peneliti (2021)

\section{Hasil Belajar Siswa}

Berdasarkan skor analisis hasil belajar siswa diperoleh dengan menggunakan SPSS 16.0 sebagai berikut : 


\begin{tabular}{cll}
\multicolumn{3}{c}{ Tabel 3 } \\
\multicolumn{3}{c}{ Hasil Belajar } \\
\hline Ukuran & Nilai \\
\hline No & Deskriptif & 70 \\
2 & Mode & 71.00 \\
3 & Median & 69.37 \\
4 & Mean & 8.349 \\
5 & Simpangan Baku & 69.712 \\
Vumber : Peneliti (2021) &
\end{tabular}

Analisis data pada penelitian ini di peroleh skor hasil belajar siswa dengan 150 responden siswa SMP Shidqia Islamic School, hasil terendah 40 dan skor tertinggi 83, rentang skor 43, rata-rata 69.37, simpangan baku 8.349, modus 70, median 71.00.

\section{Uji Normalitas}

Untuk dapat mengetahui apakah data yang dikumpulkan dan diteliti merupakan data yang berdistribusi normal atau tidak, maka penulis melakukan pengujian dengan tool SPSS 16.0, hasilnya sebagai berikut :

Tabel 4.

Uji Normalitas Data

One-Sample Kolmogorov-Smornov Test

\begin{tabular}{llrr}
\hline & \multicolumn{1}{c}{$\begin{array}{c}\text { Status sosial } \\
\text { ekonomi dan } \\
\text { Motivasi Belajar }\end{array}$} & $\begin{array}{c}\text { Hasil } \\
\text { Belajar } \\
\text { siswa }\end{array}$ \\
\hline $\mathrm{N}$ & Mean & 150 & 150 \\
Parameters & Std. Devation & 69.37 & 69.37 \\
Most & Absolute & .818 & 8.335 \\
Extreme & Positive & .093 & .094 \\
Differences & Negative & -056 & .051 \\
Kolmogorov-Smirnov Z & & -093 & -094 \\
Asymp.Sig.(2-talled) & & 1.139 & 1.156 \\
Sumber : Peneliti (2021) & & .149 & .138 \\
\hline
\end{tabular}

Berdasarkan data di atas data Status Sosial Ekonomi dan Motivasi Belajar di peroleh Kolmogorov-Smimov Z sebesar 1.139 dan nilai Asymp.Sig. (2-talled) sebesar 0.149 atau bisa di tulis sebagai nilai Probabilitas $(\mathrm{p}$-value $)=0.149>0,05$ atau Ho di terima. Kemudian data Hasil Belajar Siswa di peroleh Kolmogorov-Smimov Z sebesar 1.156 dan nilai Asymp.Sig. (2-talled) sebesar 0.138 atau bisa di tulis sebagai nilai Probabilitas (p-value) = 
0.138> 0,05 atau Ho di terima. Maka, data Status Sosial Ekonomi Orang Tua, Motivasi Belajar dan Hasil Belajar Siswa Normal.

\section{Uji Homogenitas}

Pengajian homogen di lakukan terhadap varian regresi dependen atau variabel - variabel independent dengan tool SPSS 16.0.

Tabel 5.

\section{Uji Homogenitas}

Test of Homogeneity of Variances

\begin{tabular}{cccc}
\hline $\mathrm{F}$ & $\mathrm{df} 1$ & $\mathrm{df} 2$ & Sig. \\
\hline .982 & 1 & 298 & .322 \\
\hline \multicolumn{4}{l}{ Sumber : Peneliti $(2021)$}
\end{tabular}

Dari data di atas di peroleh levene Statistik $=0.982$, df1 $=1$, df2 $=298$, dan p-value $=$ 0.322> 0,05 atau Ho di terima. Oleh karena itu, kedua kumpulan data berasal dari kelompok yang homogen.

\section{Uji Hipotesis}

Hasil uji hipotesis dengan menggunakan SPSS 16.0 sebagian berikut :

Tabel 6.

Uji Hipotesis

Coefficients

\begin{tabular}{|c|c|c|c|c|c|c|}
\hline \multirow{2}{*}{\multicolumn{2}{|c|}{ Model }} & \multicolumn{2}{|c|}{ Unstandardized } & \multirow{2}{*}{$\begin{array}{c}\text { Standardized } \\
\text { Coefficients } \\
\text { Beta } \\
\end{array}$} & \multirow[t]{2}{*}{$\mathbf{t}$} & \multirow[t]{2}{*}{ Sig. } \\
\hline & & B & Std.Error & & & \\
\hline \multirow{3}{*}{1} & (Constant) & 74.431 & 10.211 & & 7.289 & .002 \\
\hline & $\begin{array}{l}\text { Status } \\
\text { Sosial } \\
\text { Ekonomi }\end{array}$ & .017 & .141 & .010 & .118 & .007 \\
\hline & $\begin{array}{l}\text { Motivasi } \\
\text { Belajar }\end{array}$ & .095 & .144 & .055 & .657 & .002 \\
\hline
\end{tabular}

a.Dependent Variabel : Hasil Belajar Siswa

Sumber : Peneliti (2021)

Didapatkan dari kolom B, maka persamaan regresi: $\mathrm{Y}=74.431+0.17 \mathrm{X}$. Dari hasil analisis diperoleh t hit $=0.118$ dan $\mathrm{p}$-value $=0.007 / 2=0.003<0.05$ atau Ho di tolak. Dengan demikian "Status Sosial Ekonomi Orang Tua berpengaruh positif terhadap Hasil Belajar". 
Dan Diperoleh dari kolom B, sehingga persamaan regresi: $Y=74.431+0.095$ X. Dari hasil analisis diperoleh t hit $=0.657$ dan $\mathrm{p}$-value $=0.002 / 2=0.001<0.05$ atau Ho di tolak . Dengan demikian “Motivasi Beajar berpengaruh positif terhadap Hasil Belajar”.

Tabel 7. ANOVA

\begin{tabular}{ccccccc}
\hline \multirow{2}{*}{ Model } & $\begin{array}{c}\text { Sum of } \\
\text { Squares }\end{array}$ & df & $\begin{array}{c}\text { Mean } \\
\text { Squares }\end{array}$ & F & Sig. \\
\hline \multirow{4}{*}{1} & Regression & 113.568 & 1 & 113.568 & 10.793 & .002 \\
& Residual & 1.887 .176 & 298 & 63.328 & & \\
& Total & 1.324 .403 & 299 & & & \\
\hline
\end{tabular}

Sumber : Peneliti (2021)

Hipotesis statistik :

Ho : $\beta=0$ (regresi tak berarti)

Hi : $\beta \neq 0$ (regresi berarti)

Uji signifikasi persamaan garis regresi diperoleh $\mathrm{F}$ hit $=10.793$, dan $\mathrm{p}$-value $=0.002<0.05$ atau Ho di tolak. Dengan demikian regresi Y atas X adalah signifikan atau Status Sosial Ekonomi Orang Tuda dan Motivasi Belajar berpengaruh terhadap Hasil Belajar Siswa.

Tabel 8.

Model Summary

Change Statistics

\begin{tabular}{cccccc} 
Model & $\begin{array}{c}\text { R Square } \\
\text { Change }\end{array}$ & F Change & df1 & df2 & $\begin{array}{c}\text { Sig. F } \\
\text { Change }\end{array}$ \\
1 & .393 & 10.793 & 2 & 147 & .002 \\
\hline Sumber : Peneliti $(2021)$ & & & &
\end{tabular}

Uji signifikasi korelasi didapatkan hasil dari table Model Summary. Koefisien korelasi (r $\mathrm{xy})=0.393$ dan $\mathrm{F}$ hit $=0.107$ dengan $\mathrm{p}$-value $=0.002<0,05$ atau Ho di tolak. Dengan demikian koefisien korelasi X dan Y adalah signifikan. Sedangkan koefisien determinasi R Square $=0.393$, yang berarti $39,3 \%$ variabel hasil belajar siswa dapat di pengaruhi oleh status sosial ekonomi orang tua dan motivasi belajar.

Hasil penelitian ini menunjukkan adanya pengaruh status sosial ekonomi orang tua dan motivasi belajar terhadap hasil belajar siswa. Karena hal ini terlihat pada hasil belajar siswa yang cukup rendah. Berdasarkan hasil sebagian faktur pengaruh Status Sosial Ekonomi Orang Tua diperoleh 
koefisien regresi 0.017 , dan t hitung 0.118 dengan nilai signifikan 0.007 karena koefisien regresi mempunyai bernilai positif dan signifikansi $(\mathrm{p})<0,05$ bahwa Status Sosial Ekonomi Orang Tua berpengaruh positif dan signifikan terhadap Hasil Belajar Siswa SMP Shidqia Islamic School. Jadi, semakin tinggi status sosial ekonomi orang tua maka semakin tinggi juga hasil belajar siswa. Hasil penelitian ini menunjukkan bahwa status sosial ekonomi orang tua berpengaruh positif dan signifikan terhadap hasil belajar: semakin tinggi hasil belajar siswa, semakin langsung apa yang telah dipelajari dapat diterapkan dalam kehidupannya. Keluarga adalah tempat pertama anak belajar, karena dalam keluarga anak tumbuh dan berkembang dengan baik, sehingga keberadaan keluarga secara langsung maupun tidak langsung mempengaruhi keberhasilan belajar anak.

Berdasarkan hasil perhitungan secara parsial pengaruh motivasi belajar diperoleh koefisien regresi sebesar 0,095 dan t hitung sebesar 0,657 dan dengan nilai signifikansi 0,002, karena koefisien regresi bernilai positif dan signifikansi $(\mathrm{p})<0,05$, dapat disimpulkan bahwa ada pengaruh positif dan signifikan terhadap motivasi belajar Hasil Belajar Siswa SMP Shidqia Islamic School. Artinya semakin tinggi motivasi belajar siswa maka semakin tinggi pula hasil belajar siswa. Pada umumnya motivasi belajar adalah dorongan untuk belajar. Terlebih motivasi yang muncul dari dalam diri siswa itu sendiri apabila motivasi belajarnya tinggi, maka siswa akan mengikuti dengan sangat baik setiap proses pembelajaran yang dilakukan. Motivasi belajar juga berperan dalam hasil belajar siswa. Artinya setiap kegiatan belajar yang dilakukan oleh siswa akan sangat bermanfaat bagi mereka untuk mencapai hasil belajar yang baik. Motivasi belajar yang positif terlihat dalam kegiatan belajar sehari-hari. Siswa dengan motivasi belajar yang tinggi cenderung antusias dalam belajar, selalu tepat waktu dalam mengumpulkan tugastugas khusus, memiliki kemauan yang tinggi untuk berhasil, dan menjadikan kegiatan belajar sebagai suatu keharusan.

Dari hasil perhitungan secara parsial pengaruh Status Sosial Ekonomi Orang Tua dan Motivasi Belajar diperoleh koefisien regresi 74.431, dan t hitung 7.289 dengan nilai signifikan 0.002 karena koefisien regresi memiliki nilai positif dan signifikansi $(\mathrm{p})<0,05$ maka dapat disimpulkan 
terdapat pengaruh positif dan signifikan Status Sosial Ekonomi Orang Tua dan Motivasi Belajar terhadap Hasil Belajar Siswa SMP Shidqia Islamic School.

\section{SIMPULAN}

Kesimpulan hasil dari penelitian ini menunjukan terdapat pengaruh Status Sosial Ekonomi Orang Tua dan Motivasi Belajar secara positif dan signifikan terhadap Hasil Belajar Siswa di SMP Shidqia Islamic School. Keadaan sosial ekonomi orang tua dinilai rendah, pihak sekolah harus memberikan petunjuk dan informasi kepada orang tua tentang terdapatnya beasiswa yang jelas dan komprehensif agar siswa mudah mencapai hasil belajar yang prima.. Ketika motivasi belajar tinggi, siswa mempunyai keinginan dan dorongan yang sangat kuat untuk mengembangkan potensinya sehingga siswa memiliki keinginan dan kerja keras untuk mencapai hasil belajar yang unggul.

\section{REFERENSI}

Arikunto, S. (2019). Prosedur penelitian. Rineka cipta.

Creswell, J. W. (2012). Research Design: Pendekatan Kualitatif, Kuantitatif dan Mixed, terj. Achmad Fawaid. Yogyakarta: Pustaka Pelajar.

Djamarah, S. B. (1994). Prestasi belajar dan kompetensi guru. usaha nasional.

McClelland, D.C : Atkinson, J.W ; Clark, R.A \& Lowell, E.L. 1975. The Achievement Motive. New York : Irvington Publishers, Inc.

Luthans, Fred, 1981, Organizational Psychological Research, NewYork, John Wiley \& Sons Inc.

Morgan, C.T \& R.A. King. 1975. Intoduction to Psychology. Tokyo : McGraw-Hill.

Soekanto, S. (2014). Sosiologi suatu pengantar.

Winkel W.S. 1983. Psikologi pendidikan dan evaluasi belajar. Jakarta : PT. Gramedia. Winkel W.S. 1987. Psikologi pengajaran. Jakarta : PT. Gramedia. 
Fimansyah, D. (2015). Pengaruh Strategi pembelajaran dan minat belajar terhadap hasil belajar matematika. Judika (Jurnal Pendidikan UNSIKA), 3(1).

Siti, N. (2015). Hubungan Antara Minat Belajar Dengan Hasil Belajar Pendidikan Kewarganegaraan Siswa Kelas Vi Mi Negeri Batur Kecamatan Ceper Kabupaten Klaten Tahun Pelajaran 2015/2016 Universitas Widya Dharma.

Yudhawati dan Danny. (2017). Pengaruh Lingkungan Keluarga, Kedisiplinan Siswa, Dan Motivasi Belajar Terhadap Hasil Belajar Ekonomi Siswa Di SMA Negeri 7 Surabaya. Jurnal 